\title{
MITIGATION OF DAMAGE CAUSED TO DRINKING WATER AND SEWAGE PIPES DURING SEISMIC AND HYDROLOGICAL EPISODES
}

\author{
RAMÓN EGEA PÉREZ ${ }^{1}$, JESÚS P. CHAZARRA ZAPATA², FRANCISCO J. PÉREZ DE LA CRUZ ${ }^{3}$ \& \\ FRANCISCO J. LÓPEZ PEÑALVER ${ }^{4}$ \\ ${ }^{1}$ EMUASA, Municipal Water and Sanitation Company, Spain \\ ${ }^{2}$ Engineering Department, University Miguel Hernandez, Spain \\ ${ }^{3}$ Polytechnic University of Cartagena, Spain \\ ${ }^{4}$ Superior Polytechnic School, Alicante University, Spain
}

\begin{abstract}
In the present investigation, the development and implementation of different typologies of elements and devices that increase the reliability of pipes of a fragile nature is proposed. This ensures continuity of a drinking water supply and sewerage, which is especially necessary during and after natural disasters related to hydrology and seismicity, and is even more necessary to alleviate its adverse effects. Drinking water supply and sanitation networks, as basic elements of urban water infrastructure, can generate a high degree of vulnerability in the case of a seismic movement or an episode of heavy rain, which requires the adoption of new designs of elements or devices and resilient materials to absorb the stresses generated and the mechanical loads occurring during such risk episodes. Experience has shown that the piping of metallic materials (ductile iron, steel, and other alloys), and reinforced concrete, although more rigid than plastic pipes (polyethylene, PVC, fiberglass reinforced polyester PRFV), has a capacity to absorb movements, which is mainly due to the one provided by the unions, since it generates a flexibility as a whole (pipe and joints) that improves the behavior of the system (increases "ductility") that decreases the vulnerability of linear hydraulic infrastructures. The selection, analysis and application of these elements is fundamental to improving the reliability of these basic urban infrastructures, especially in areas exposed to hydrogeological risks, such as Southeastern Spain with a moderate probability of seismic events of an intensity higher than VII, and with episodes of intense rains of torrential nature, and their derived risks. The increase in the resilience provided by these elements or devices will increase the operational reliability of the linear hydraulic system of potable water and sewage, reducing the degree of vulnerability of the same, and mitigating economic, social and environmental damages.
\end{abstract}

Keywords: resilience, vulnerability, natural hazards, seismic, hydrological, risk, sustainability, reliability.

\section{INTRODUCTION}

From the analysis performed, strategies are presented to mitigate the possible anomalous effects generated by the seismic movements and those induced by intense rainfall events. For this purpose, the nature of the ground layers located in the consolidated subsoil is considered and it is recommended the provision of specific foundation elements that distribute the loads and standardize the possible induced differential seats, as well as the use of "dynamic" anchor elements in Linear Hydraulic Infrastructure and specific installation procedures.

During the last few years, some low intensity seismic movements $(<3$ IMM) have been registered and located in the Southeastern area of the municipality of Murcia, as shown in the following graphs (Figs 1 and 2).

At the same time, and based on different studies of seismic information in the European Mediterranean Area [1], the values of peak ground acceleration (PGA) and peak ground velocity (PGV) for its application to the City of Murcia, Fig. 3. 
The behavior of the characteristic soil in the metropolitan area of the city of Murcia, its evolution in relation to the oscillation period and the seismic acceleration spectrum (NCSE02 and RISMUR-I) also has been analyzed, obtaining the following Fig. 4, [4].

According to the classification of land established by NEHRP-2009 and RISMUR 2015, the seismic parameters (PGA, and Vs), as well as the specific density, $\gamma$ of the terrain in the research carried out were obtained.

For the characterization of the land, several surveys have been carried out in the metropolitan area of Murcia, and in districts close to the city, with potential liquefaction of the surface soil layers $(<30 \mathrm{~m})$, which may affect the operation of hydraulic infrastructures.

Fig. 5 is an average characterization of the terrain typology, according to the depth of the strata, as well as the correlation with the spectral velocity (Vs) and the maximum terrain acceleration (PGA) [3]-[5].

Seismic events in the municipality of Murcia Period 2011-2017 (April)

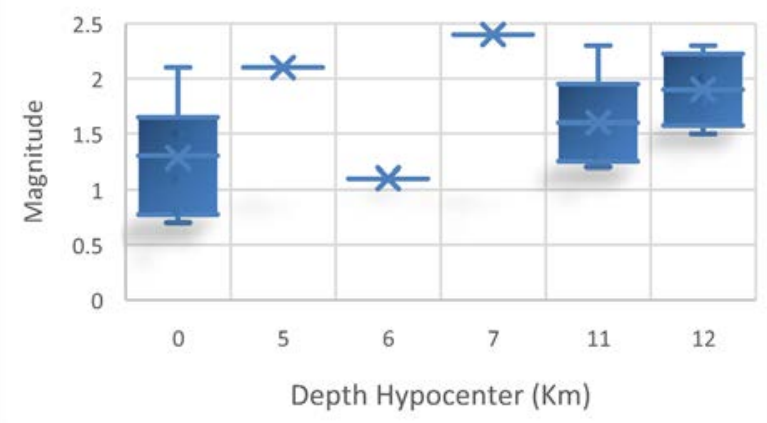

Figure 1: Box diagram. Epicentral distance of different seismic events in the municipality of Murcia. (Source: IGN.)

\section{Zonal Location}

Seismic events in the municipality of Murcia Period 2011-2017 (April)

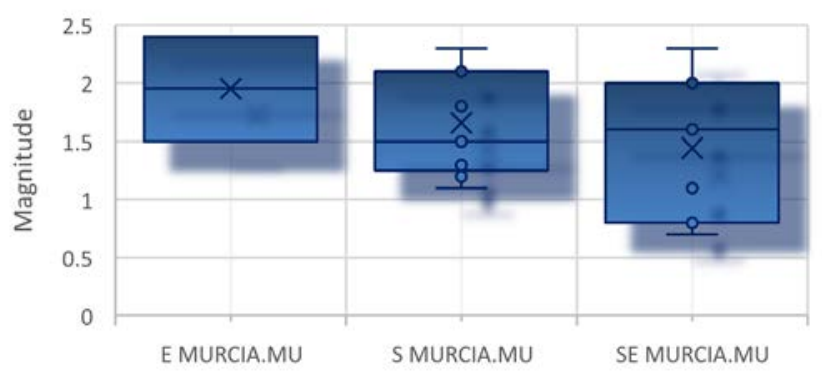

Figure 2: Box diagram. Zonal location of different seismic events in the municipality of Murcia. (Source: IGN.) 


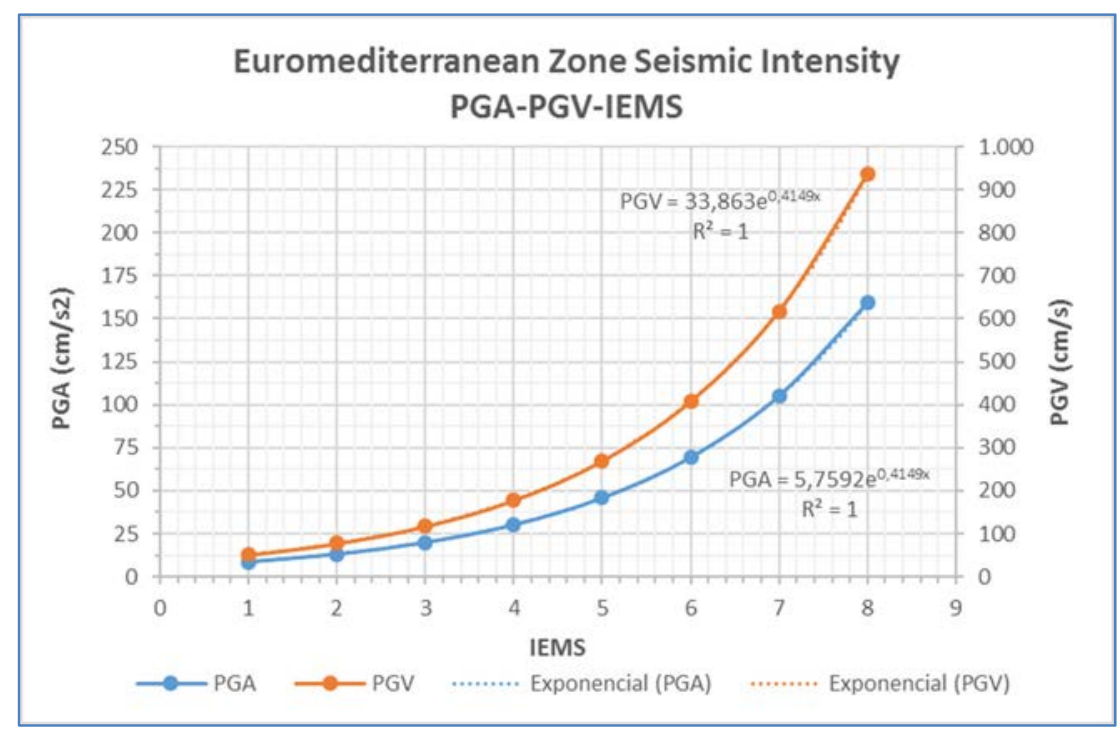

Figure 3: Representation of the PGA and the PGV related to the seismic intensity in the Euro-Mediterranean Zone. Specific formulations.

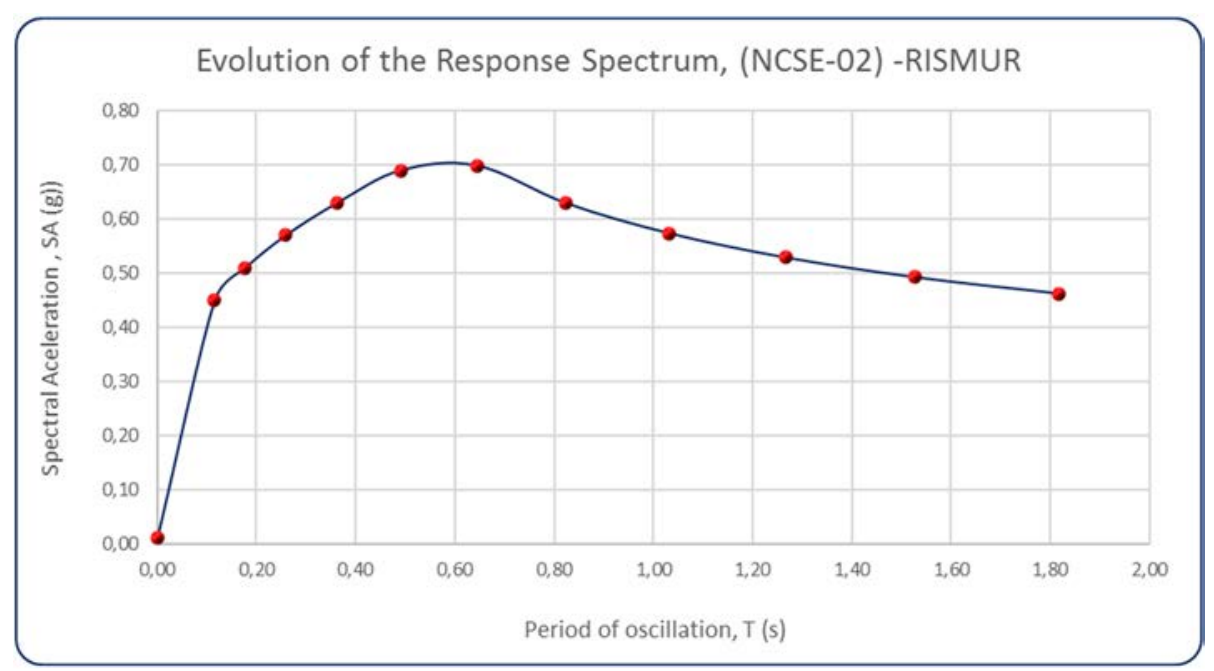

Figure 4: Graph of evolution of the spectral acceleration-SA, (g), and the period of oscillation T, (s) of the terrain in metropolitan area of the city of Murcia. Adapted according to RISMUR-I. (EMUASA.) 


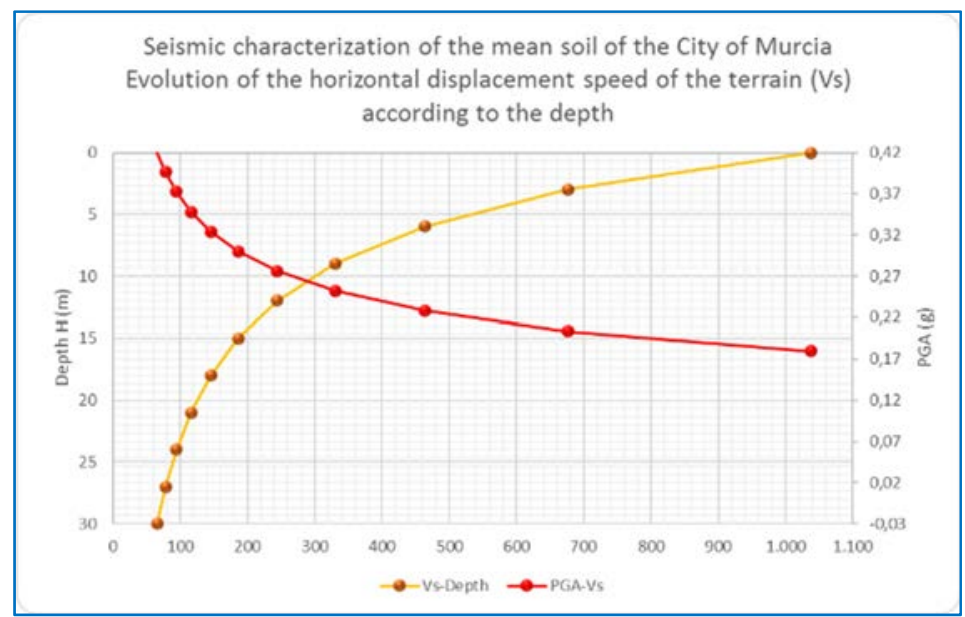

Figure 5: Seismic characterization of the mean soil of the City of Murcia. Evolution of the horizontal displacement speed of the terrain (Vs) according to the depth.

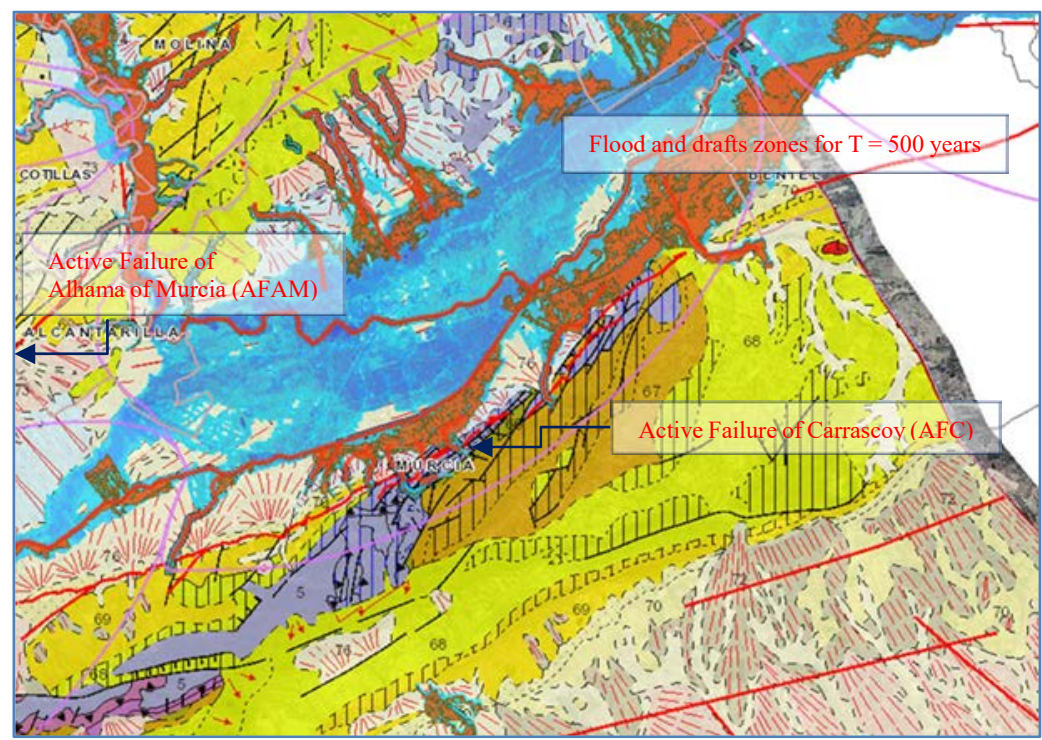

Figure 6: Seismic characterization of the mean soil of the City of Murcia. Evolution of the horizontal displacement speed of the terrain (Vs) according to the depth [6].

The previous analysis of the zonal hydrogeological characteristics is another essential factor to apply the typology of dissipating element or channel of the potentially destructive energy, to develop the resilience in the Linear Hydraulic Infrastructure.

We also analyze the geological characteristics (active faults), hydrogeological characteristics and the potential for subsidence of the land near the urban environment of the city of Murcia, Fig. 6. 
Table 1: Circumferential rigidity (Sc) and degree of elasticity of pipes (1).

\begin{tabular}{|l|l|}
\hline $\mathrm{Sc}<10 \mathrm{Tons} / \mathrm{m} 2$ & Flexible Pipes \\
\hline $10 \leq \mathrm{Sc} \leq 20 \mathrm{Tons} / \mathrm{m} 2$ & Semi-rigid pipes \\
\hline $\mathrm{Sc}>20 \mathrm{~T} / \mathrm{m} 2$ & Rigid Pipes \\
$\qquad S_{c}=\frac{\mathrm{E}}{12} \cdot\left(\frac{\mathrm{e}}{\mathrm{D}_{\mathrm{m}}}\right)^{3}$,
\end{tabular}

where:

E: elastic material module of the pipe $\left(\right.$ Tons $\left./ \mathrm{m}^{2}\right)$.

e: thickness of the tube (m).

Dm: average pipe diameter (De-e), en $m$.

In relation to the factors that characterize the Linear Hydraulic Infrastructure, there is an essential factor in the behavior of the pipes during seismic and hydrological episodes, it is the rigidity of the pipe-land set, since in the case of flexible pipes $\left(\mathrm{Sc}<10 \mathrm{Tons} / \mathrm{m}^{2}\right)$ Amster K. Howard of the United States Bureau of Reclamation [7], introduces circumferential stiffness as a parameter that delimits the dynamic behavior of the same as shown in Table 1.

As Howard indicates, according to the geometry of the pipe (diameter and thickness), it can have a flexible or rigid behavior.

Similarly, Standard UNE-EN 805, and the Technical Guide on pipelines for the transport of pressurized water (CEDEX, 2003), establishes the methodology for calculating relative stiffness (2):

$$
S_{r}=\frac{\mathrm{E}_{\mathrm{S}}}{8 \cdot S \cdot\left(1-v_{\mathrm{S}}^{2}\right)}
$$

where:

$E_{s}$ : elastic reaction module of trench fills $\left(\right.$ Tons $\left./ \mathrm{m}^{2}\right)$.

$\mathrm{S}$ : circumferential rigidity of the pipe (Tons $/ \mathrm{m}^{2}$ ).

$\mathrm{v}_{\mathrm{s}}$ : Poisson coefficient of the soil, usually 0,3 .

And the classification of the different typologies of materials according to the greater or lesser degree of rigidity:

$$
\text { PRFV }<\text { STEEL }<\text { PE }<\text { PVC-U }<\text { DF }<\text { ASBEST-CEMENT }<\text { CONCRETE }
$$

Likewise, with respect to the degree of ductility, the pipes can be classified into fragile and ductile, as shown in Table 3.

Characterizing the supply and sanitation networks based on the specific information and the criteria presented, we analyze and propose a different typology of devices or components whose resilience will be adapted to an efficient and sustainable operational management, through effective planning and sequential implementation, based on the established criteria of criticality.

Table 2: Relative rigidity ( $\mathrm{Sr}$ ) and degree of elasticity of pipes.

\begin{tabular}{|l|l|}
\hline $\mathrm{Sr} \leq 9$ & Rigid behavior \\
\hline $\mathrm{Sr}>9$ & Flexible behavior \\
\hline $9<\mathrm{Sr}<24$ & Semi-rigid behavior \\
\hline
\end{tabular}


Table 3: Classification of pipes according to material, degree of ductility or fragility and service (drinking water and sewage supply).

Drinking water

\begin{tabular}{|l|l|}
\hline Fragile Pipes & \multicolumn{1}{|c|}{ Ductile pipes } \\
\hline Asbest Cement (AC) & $\begin{array}{l}\text { Ductile Casting } \\
(\text { HD) }\end{array}$ \\
\hline $\begin{array}{l}\text { Reinforced concrete } \\
\text { pipes with sheet steel } \\
\text { (RCSS) }\end{array}$ & $\begin{array}{l}\text { Galvanised steel } \\
(S G)\end{array}$ \\
\hline Gray cast iron (GI) & Stainless steel (SS) \\
\hline \multirow{2}{*}{} & $\begin{array}{l}\text { Steel (S) } \\
\text { Polyethylene } \\
\text { (PEHD) }\end{array}$ \\
\cline { 2 - 2 } & $\begin{array}{l}\text { Polyester } \\
\text { reinforced with } \\
\text { fiberglass (PRFV) }\end{array}$ \\
\end{tabular}

\section{Sewage}

\begin{tabular}{|l|l|}
\hline Fragile Pipes & Ductile pipes \\
\hline $\begin{array}{l}\text { Asbest Cement } \\
(A C)\end{array}$ & $\begin{array}{l}\text { Ductile Casting } \\
(\text { HD) }\end{array}$ \\
\hline $\begin{array}{l}\text { Concrete Iron } \\
(C I)\end{array}$ & $\begin{array}{l}\text { Galvanised steel } \\
(S G)\end{array}$ \\
\hline \multirow{5}{*}{} & Stainless steel (SS) \\
\cline { 2 - 2 } & Steel (S) \\
\cline { 2 - 2 } & Polyethylene (PE) \\
\hline & $\begin{array}{l}\text { PVC } \\
\text { Polyester } \\
\text { reinforced with } \\
\text { fiberglass (PRFV) }\end{array}$ \\
\cline { 2 - 2 } & $\begin{array}{l}\text { Corrugated PVC } \\
\text { (PVCC) }\end{array}$ \\
\hline
\end{tabular}

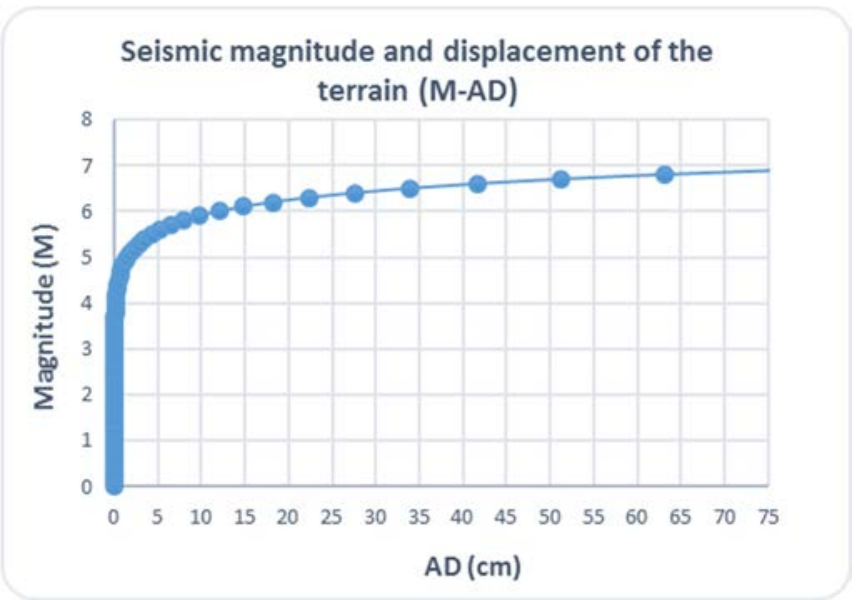

Figure 7: Correlation seismic magnitude (M), and displacement of the terrain (AD).

It is possible to estimate the average displacement caused by an earthquake as a function of magnitude (M). Using empirical formulations of earthquake regressions, such as the Wells \& Coppersmith regression, 1994, we can know the average displacement (AD) of an earthquake that responds to the equation: $M=6.93+0.82 \log (A D)$, [8]. Thus, it is possible to obtain probable displacement according to the hydrogeological susceptibility of each hydraulic sector (Supply system), and each hydraulic basin (Urban sanitation and drainage system), Fig. 7. 
Once the different zones of different susceptibility to hydrogeological risk have been defined, the infrastructures are classified according to their degree of criticality, operational parameters and service alternatives.

A planning for the development of the resilience of the Hydraulic Infrastructure System was established, considering the type of materials most appropriate to the area of application, the specific alert and monitoring devices, and the energy dissipation devices and/or insulators in its area.

Finally, the appropriate anti-seismic devices are analyzed and developed according to the established criteria, carried out risk characterization and established operational.

The following shows various incidents caused by hydrogeological events in the Potable Water Infrastructures of Southeastern Spain.

Next, the milestones of the present investigation are summarized, which are proposed in the following methodology:

- Characterization and preliminary analysis of the response capacity of the Linear Hydraulic Infrastructure (Degree of resilience).

- Analysis of variables and characteristic parameters of the zonal hydrogeological risks, with potential affect, to the Linear Hydraulic Infrastructure.

- Proposal of planning and prioritization of actions to be performed for the implementation of specific components and devices that increase resilience in the System.

- Integration of resilience in the Operational Management of the Urban Linear Hydraulic Infrastructure.
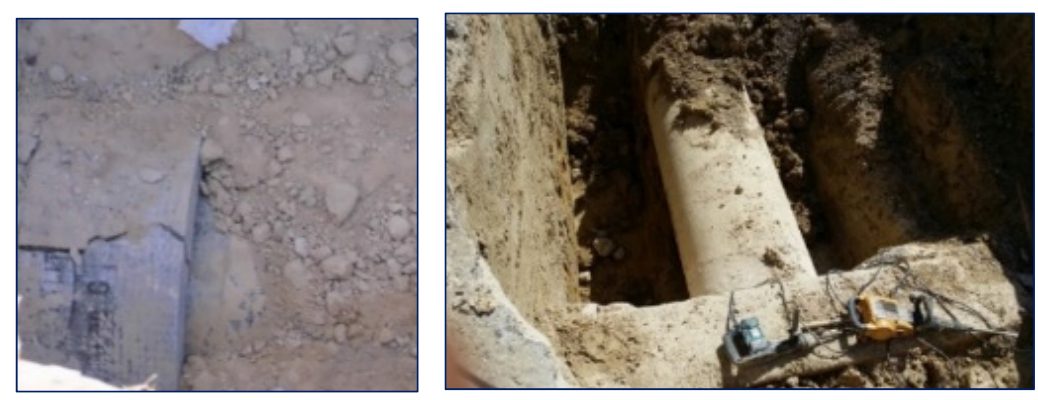

Figure 8: Detail of breakages in Asbeste cement pipes (Guardamar of Segura). Seismic event, July 12, 2015. MCT [9].
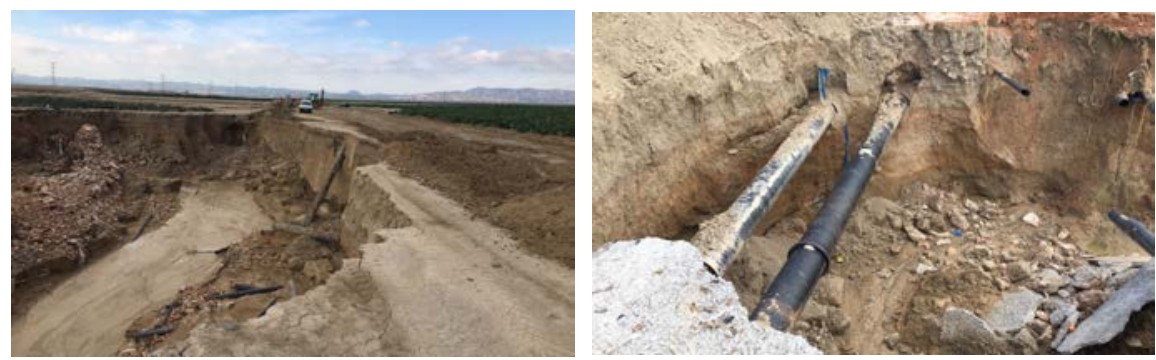

Figure 9: Detail of breakages in various types of pipes (Roldan, Murcia). Hydrological event in December 2016 [9]. 


\section{METHODOLOGY}

The integration of these risks in the Hydraulic Infrastructures System favors the resilience of the latter and the efficient planning of the actions to be performed, and the management thereof, guaranteeing its reliability and its operation as critical infrastructure.

Next, each of the phases of the proposed methodology, its planning, the sequential development, the implementation processes, and the specific typologies of devices are described in a schematic way.

Fig. 12 shows the different types of anti-seismic systems, whether insulators or energy dissipaters, for the protection of the different components of the hydraulic infrastructure.

The implementation of this integral methodology, increases, develops and plans the resilience in the System increasing the level of service and the operational evolution in real time, improving decision making.

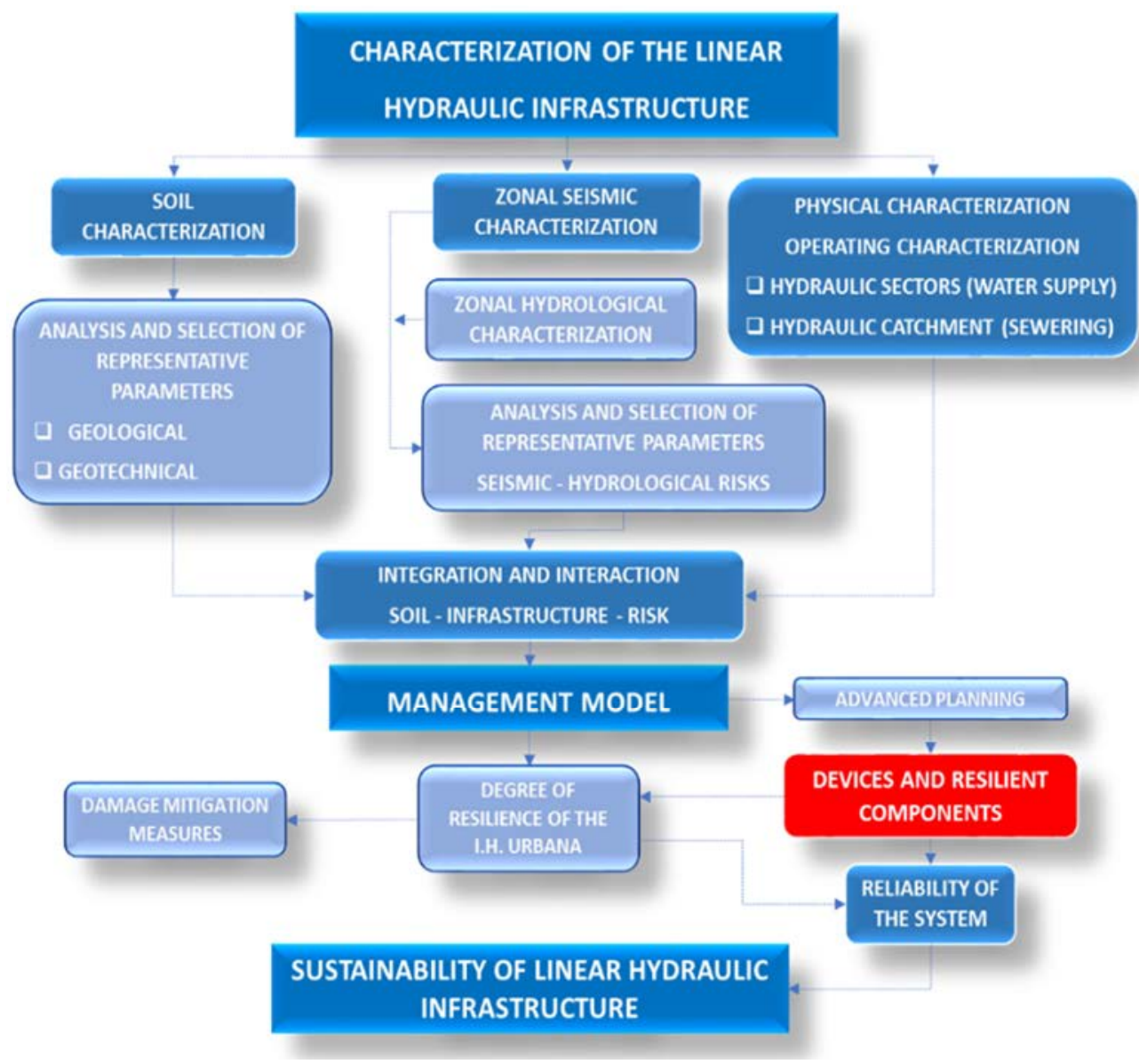

Figure 10: Flow diagram of the different stages of development of the proposed methodology. The Characterization of the Linear Hydraulic Infrastructure, the Implementation of the Resilience and the Sustainability of the Linear Hydraulic Infrastructure in Relation to the Seismic and Hydrological Risks. (Source: EMUASA.) 


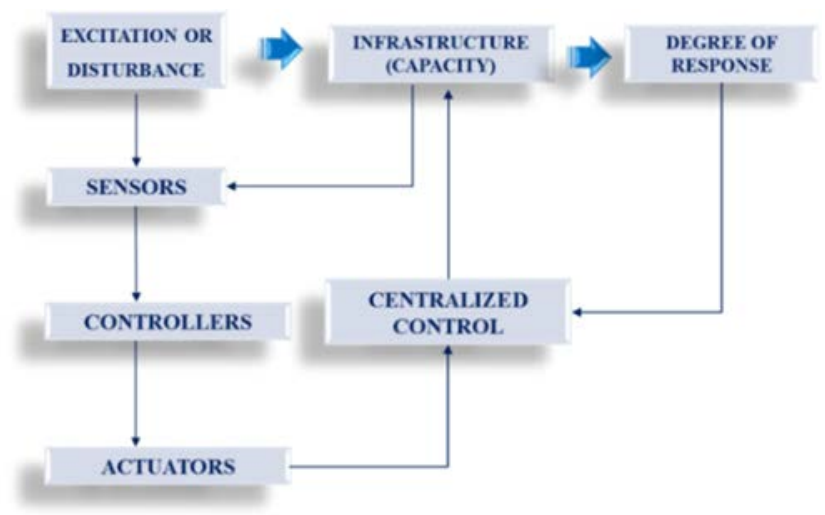

Figure 11: Functional response scheme (active control) of the System, in response to a seismic and / or hydrological event. Development of the resilience of the linear Hydraulic Infrastructure system. (Source: EMUASA.)

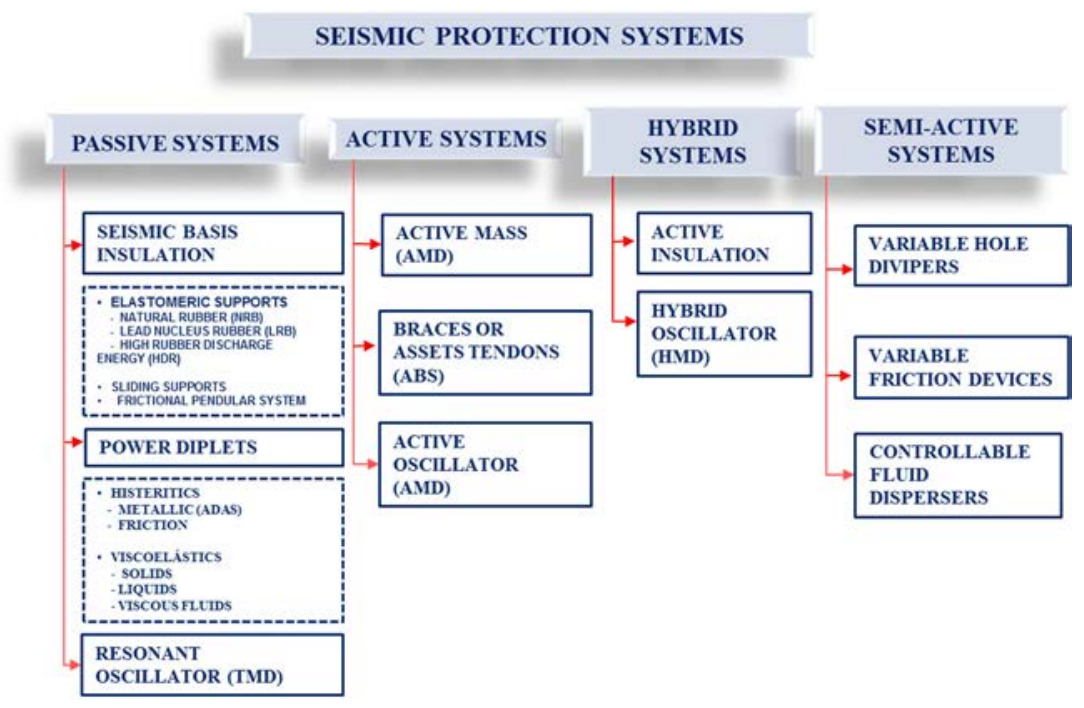

Figure 12: Schematic of the different seismic protection systems to be implemented in the Linear Hydraulic Infrastructure. (Source: EMUASA.)

\section{RESULTS AND DISCUSSION}

The resilient elements proposed will greatly mitigate the adverse effects of these events on the Hydraulic Infrastructure, prioritizing their implementation according to the criticality of the sectors and the hydraulic basins that make up the mathematical models of operation of the potable water network and sanitation of the city of Murcia.

This implementation, which will be adapted to the physical and operational characteristics of the network, the diverse seismic and hydrological susceptibility of each zone, represents a new vision in the Integral Management of Urban Supply Services, since it will unify Efficient Management and Sustainability of the System in a dynamic climate change framework [10]. 
Hereinafter, by way of example, different devices, Figs 13-16, which protect potable water lines against any movement of the ground or anomalous operation of the System, are provided.

As already indicated, the integral planning of the infrastructure system and designs of a selective action strategy is essential, and for this it is necessary to analyze the various hydraulic components existing in the market, and integrate them into the System according to the characterization described and the methodology proposed in the present investigation.

Within the extensive range of existing components and materials that largely meet the needs of Urban Supply Systems, the following are shown for their innovative and advanced features:
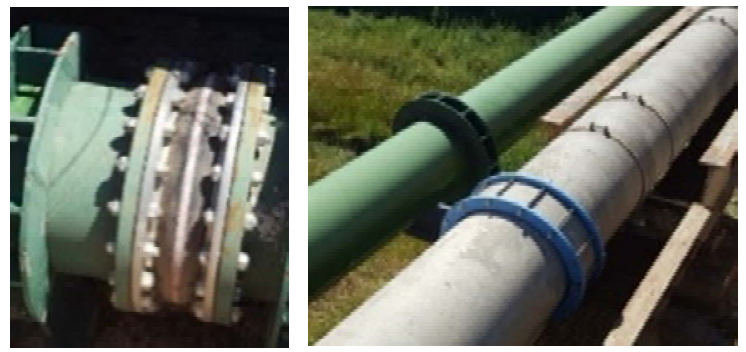

Figure 13: Energy dissipating device or movement compensators. (Source: EMUASA.)
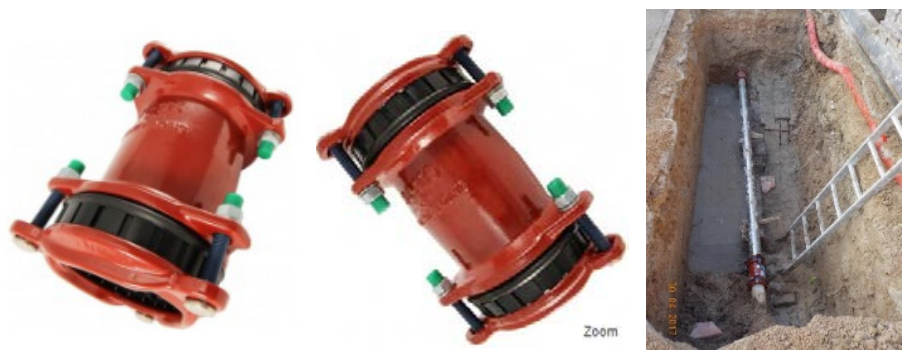

Figure 14: Repair work on a potable water pipe, incorporating a length of DN-80 mm stainless steel pipe with flexible joints, allowing up to 8 degrees of angular deflection, in the DN-80 mm pipe of asbestos cement. It is an example of increasing resilience in relation to the uniformity of the rigidity of the distribution network, in this case. (Source: EMUASA.)
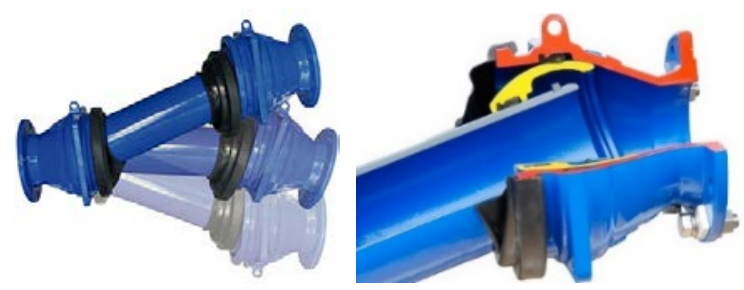

Figure 15: Special device for the resilience of the potable water network against seismic movements of high intensity IMM> VII. (Source: GEOFLEX-SAINT GOBAIN PAM.) 


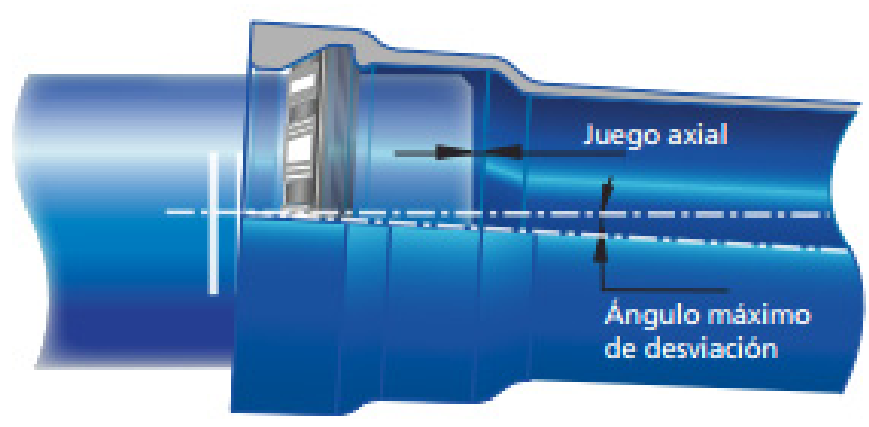

Figure 16: Type of joint or automatic joint in ductile cast iron pipes, has an angular deflection greater than five degrees and a flexural strength appropriate to earthquakes of moderate intensity. (Source: SAINT GOBAIN PAM.)

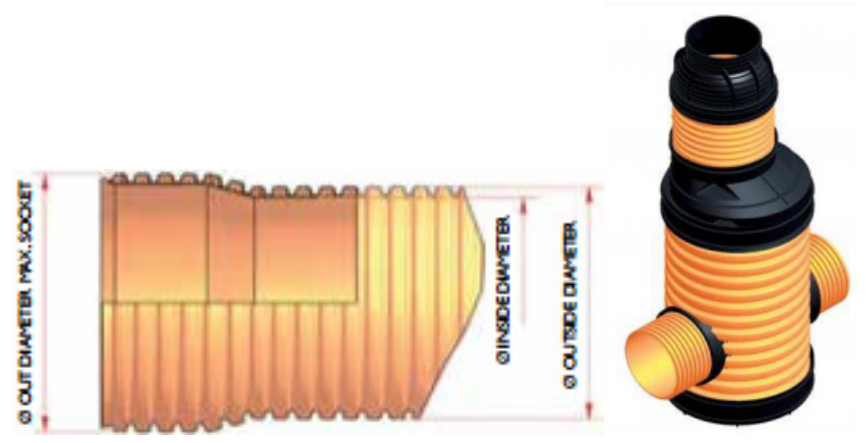

Figure 17: Corrugated PVC pipes and variable diameter log well. Adequa-Uralita. The flexible joints allow an angular deflection between two and nine degrees according to the diameter of the pipe. They are ideal for seismic zones, avoiding the typical breaks in pipe-well joints in the case of sanitation networks, due to excessive variability in the rigidity of the elements.
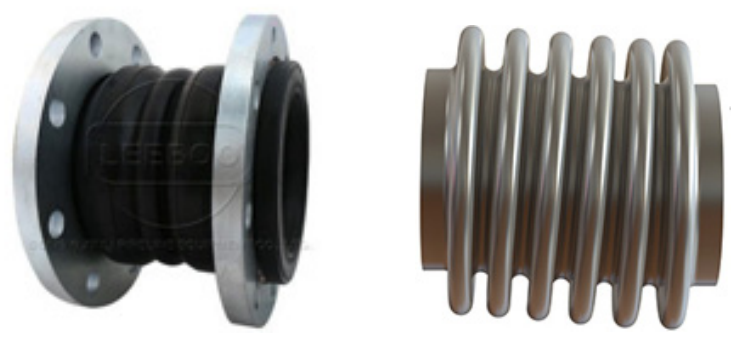

Figure 18: This kind of strap type bonding is recommended in transitional sections of different types of materials, areas of special seismic susceptibility or flood zones, and pressure variability that can absorb important deflections without losing the structural resistance properties, stress of compression and of traction, and the sealing. 
Table 4: Nature pipe material and angular deflection.

\begin{tabular}{|l|c|}
\hline \multicolumn{1}{|c|}{ Pipes } & $\begin{array}{c}\text { Angular } \\
\text { deflection }\end{array}$ \\
\hline Ductile Iron (DI) & $5^{\circ}-7^{\circ}$ \\
\hline Corrugated polyvinyl chloride (CPVC) & $2^{\circ}-9^{\circ}$ \\
\hline Polyester reinforced with glass fiber & $0.5^{\circ}-3^{\circ}$ \\
\hline Stainless Steel (SS) & $5^{\circ}-7^{\circ}$ \\
\hline Concrete (C) & $10-40 \mathrm{~mm} / \mathrm{m}$ \\
\hline Polyvinyl chloride (PVC) & $2^{\circ}$ \\
\hline HD polyethylene (HDPE) & $3^{\circ}$ \\
\hline
\end{tabular}

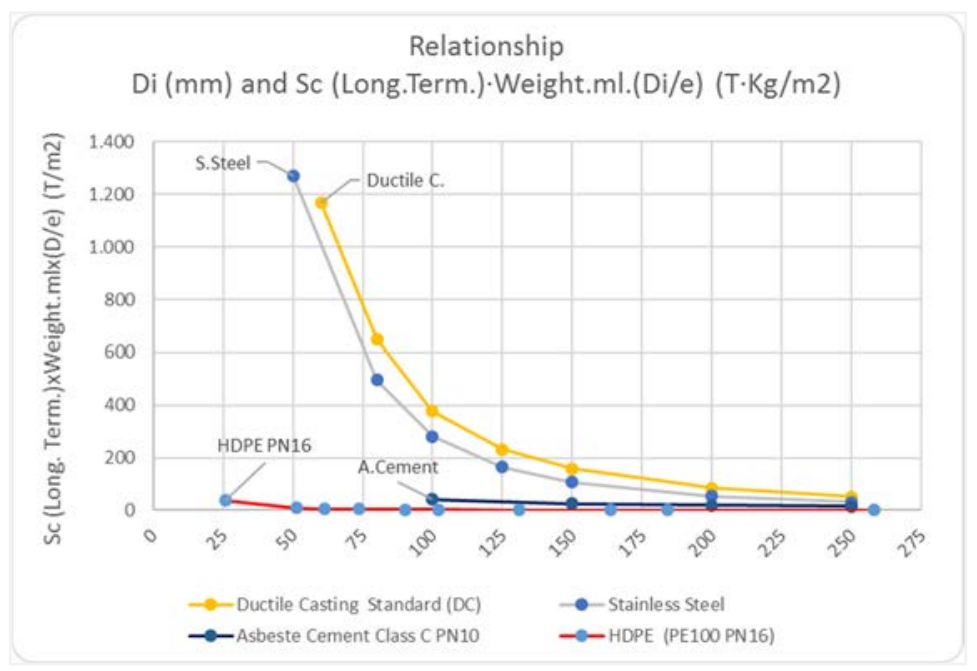

Figure 19: This graph relates the inside diameter of the pipe (Di) and the proposed index \{Circumferential stiffness divided by the weight per meter of pipe by [Inside diameter/thickness]\}, and it has an index that allows to correlate the rigidity characteristics of the pipe according to the diameter of the pipe, and the most related materials and homogenize the behavior of the same in the face of seismic and hydrogeological risks in general.

In the last decade, the use of composite materials and in large measure the reinforced plastics has proliferated. Its use has been reinforced by its characteristics of durability and ability to absorb movements and settlements of the terrain, although their efficient use requires a previous and specific analysis and an application methodology as the one proposed in this study [11]-[13].

The angular deflections of some of the most commonly used materials in linear hydraulic infrastructures are summarized in Table 4.

Fig. 19 relates the circumferential rigidity of various materials and pipe diameters, the weight per linear meter and the relationship between the internal diameter and the thickness. 
The evolution of the parameters of "induced ductility" is observed according to the nature of the material and the diameter, Fig. 19.

\section{CONCLUSIONS}

This research proposes the implementation of a new innovative methodology adapted to the development of new materials, and their adaptation to the requirements of the Urban Hydraulic Infrastructure Managers, which must further integrate resilience, for the sustainability of the System in a more dynamic climate and climate change.

An integrated and resilient characterization, specific to the linear supply and sewage infrastructure, has been proposed through:

The increase and development of resilient elements in the components of linear infrastructure to reduce the vulnerability.

By means of the analysis of the hydrogeological zonal risks, with affection to the linear hydraulic infrastructure, the representative parameters are obtained.

The development of specific analyzes and the realization tests of composite materials, and their adaptation to the geological and geotechnical characteristics of the soils.

Application of different materials according to the different types of risks in each sector or hydraulic basin.

Proposal of indices representative of the stiffness and angular deflection of joints according to the estimated displacement in the seismic zonal analysis.

The rationalization of means and the application of specific elements that mitigate the damages generated by catastrophic events of hydrogeological origin.

As a conclusion to the present investigation, it is indicated that the definition of the constituent components of the urban hydraulic system, the analysis of its vulnerability based on the variables and parameters proposed, and the indices that define it, besides the type of management of the with an integral vision, is an essential tool to guarantee the operation of the system in the case of seismic and hydrological events.

In further research, it would be useful, among other analyzes, to develop the interaction between the different types of joining accessories and the rigidity of the pipes, and to establish the range of movements according to the seismic susceptibility of each sector or hydraulic basin.

$P G A=$ Peak ground acceleration $\left(\mathrm{g} \circ \mathrm{m} / \mathrm{s}^{2}\right)$.

\section{NOTATION}

$P G V=$ Peak ground velocity $(\mathrm{cm} / \mathrm{s} \mathrm{o} \mathrm{m} / \mathrm{s})$.

$P G D=$ Peak ground displacement (cm o $\mathrm{m})$.

$A D=$ Displacement terrain $(\mathrm{cm})$.

$M \quad=$ Magnitude.

\section{ACKNOWLEDGEMENT}

The authors wish to thank EMUASA their cooperation in conducting this study, without which this study would not have been possible.

\section{REFERENCES}

[1] Akkar, S. \& Bommer, J.J., Empirical equations for the prediction of PGA, PGV and spectral accelerations in Europe, the Mediterranean Region and the Middle East. Seismological Research Letters, 81(2), pp. 195-206, 2010. 
[2] Borcherdt, R.D., Estimates of Site-Dependent Response Spectra for Design (Methodology and Justification). Earthquake Spectra: November 1994, 10(4), pp. 617-653, 1994.

[3] ALA, Development of Guidelines to Define Natural Hazards Performance Objectives for Water Systems, 1, ASCE, FEMA and NIBS, 2002.

[4] ALA Wastewater System Performance Assessment Guideline, Part I and II, FEMA and NIBS, 2004.

[5] ALA, Seismic Guidelines for Water Pipelines, ASCE, FEMA and NIBS, 2005.

[6] Tsige, M. \& García Flórez, I., Proposed Geotechnical-amplification classification of geological materials in Murcia. Geogaceta, pp. 39-42, 40, 2006. ISSN: 0213683X.

[7] Howard, A.K., Technical Service Center, Bureau of Reclamation. Pipe Bedding and Backfill, 1996.

[8] Wells, D.L. \& Coppersmith, K.J., New empirical relationships among magnitude, rupture length, rupture width, rupture area and surface displacement. Bull. Seism. Soc. Am., 84, pp. 974-1002, 1994.

[9] Manual to Handle the Inundations Caused by Matrices Rupture of Potable Water or Waste Water Colectors, Online. http://www.siss.gob.cl/577/w3-printer-8208.html. Accessed on: 15 Jun. 2016.

[10] American Lifelines Alliance. Seismic fragility formulations for water systems. Part 1 - Guideline, ASCE-FEMA, pp. 104, 2001.

[11] ATC-13 (Applied Technology Council), Earthquake Damage Evaluation Data for California, Redwood City, CA: Applied Technology Council, 1985.

[12] ATC-25 (Applied Technology Council), A model methodology for assessment of seismic vulnerability and impact distribution of water supply systems, Report No: ATC-25-1, Redwood City, CA, 1992.

[13] Bardakjian, H.H., McReynolds, M. \& Zarghamee, M., ASCE 2011. Review of performance of gasketed joints of buried concrete and steel pipelines in California after recent seismic events, 2011. 